\title{
Application of Search Group Algorithm for Automatic Generation Control of Multi-area Multi-source Power Systems
}

\author{
Dillip Khamari, Rabindra Kumar Sahu*, and Sidhartha Panda \\ Department of Electrical Engineering, Veer Surendra Sai University of Technology (VSSUT), Burla-768018, Odisha, India
}

\begin{abstract}
This paper proposes a new Search Group Algorithm based PID controller, to deal with Automatic Generation Control of two-area with six unit power system. The supremacy of SGA tuned PID controller is being shown using the comparative study with Firefly Algorithm (FA) optimization method for the same test system using ITAE as an objective function. It has been demonstrated that SGA tuned PID controller improves the performance in a large compared with FA tuned PID controller. Furthermore variation in nominal values of operating load condition and system parameters with the position of step load perturbation is being carried out to achieve sensitivity analysis. From the result of sensitivity analysis it clearly depicts the robustness of the suggested method (SGA with PID controller) for two-area with six unit power system in AGC. Finally for better investigation, the proposed method is also examined by applying randomization in step load.
\end{abstract}

\section{Introduction}

Power systems arena is thriving day by day which leads to consider a major factor as Automatic Generation Control (AGC) for stable and secure power system operation. AGC plays a vital role to maintain the consistency in frequency with tie-line power. There is a great gap between electrical load demand and power generation which leads to deviation in outcomes. AGC nullifies the Area Control Error (ACE) using calculation with respect to corresponding load change in each area by adjusting automatically the generator set points. ACE is defined as the linear combination of frequency variation to the corresponding distortion in net tie-line power interchange [1-5]. Researchers are proposed number of control schemes in AGC of power systems to achieve optimized result.

The authors were investigated the different AGC based generic controllers in multi-area multi-source power system [6-9]. Sharma et al. have presented optimal design of AGC regulator controller in frequency regulation of multi-area power system with diverse power generating units [10]. Guha et al. have proposed Grey Wolf Optimization (GWO) based classical controller with PI/PID structure for AGC in multi-area power systems [11]. Saroj et al. have presented the supremacy of Firefly Algorithm tuned PID controller of two-area interconnected power system for AGC [12]. The effectiveness of AGC is not limited to artificial intelligence techniques simultaneously it depends on objective function as well the controller structure chosen which is clearly signifies from past literature.
Recently, metaheuristic based algorithm known as the Search Group Algorithm (SGA) is being proposed by Matheus Silva Goncalves et al. for the application to truss structure [13]. SGA is a population oriented search algorithm which maintains the balance in the design domain between the exploration \& exploitation.

The novel contributions in this paper are:

(i) The demonstration of the superiority of new powerful computational intelligence technique like SGA over FA tuned PID controller for AGC

(ii) To show robustness of SGA based PID controller. Here, two area six unit like hydro, gas and thermal units are taken for investigation [14]. The empirical analysis result reflects the supremacy of the suggested method. Lastly, to show the effectiveness of the tuned controller parameters, variation in nominal values of system parameters, operating load condition with the position of SLP is carried out to achieve sensitivity analysis.

\section{Proposed Method}

\subsection{Power System modelling:}

Firstly,2-area with 6-unit power system is demonstrated in Fig.1. The nominal loading is being contributed based on the decision of the participation factor assigned by each unit. After summing each control participation factor the outcome should be equivalent to unity. Participation factor for hydro, gas and thermal units are evaluated as $32 \%, 13 \%$ and $55 \%$ respectively. The system parameters values are represented in Appendix. Regulation parameters $\mathrm{R}_{1}, \mathrm{R}_{2}$ and $\mathrm{R}_{3}$ shown in Fig. 1 denotes thermal, hydro and gas unit respectively.

\footnotetext{
* Corresponding author: rksahu_ee@vssut.ac.in
} 


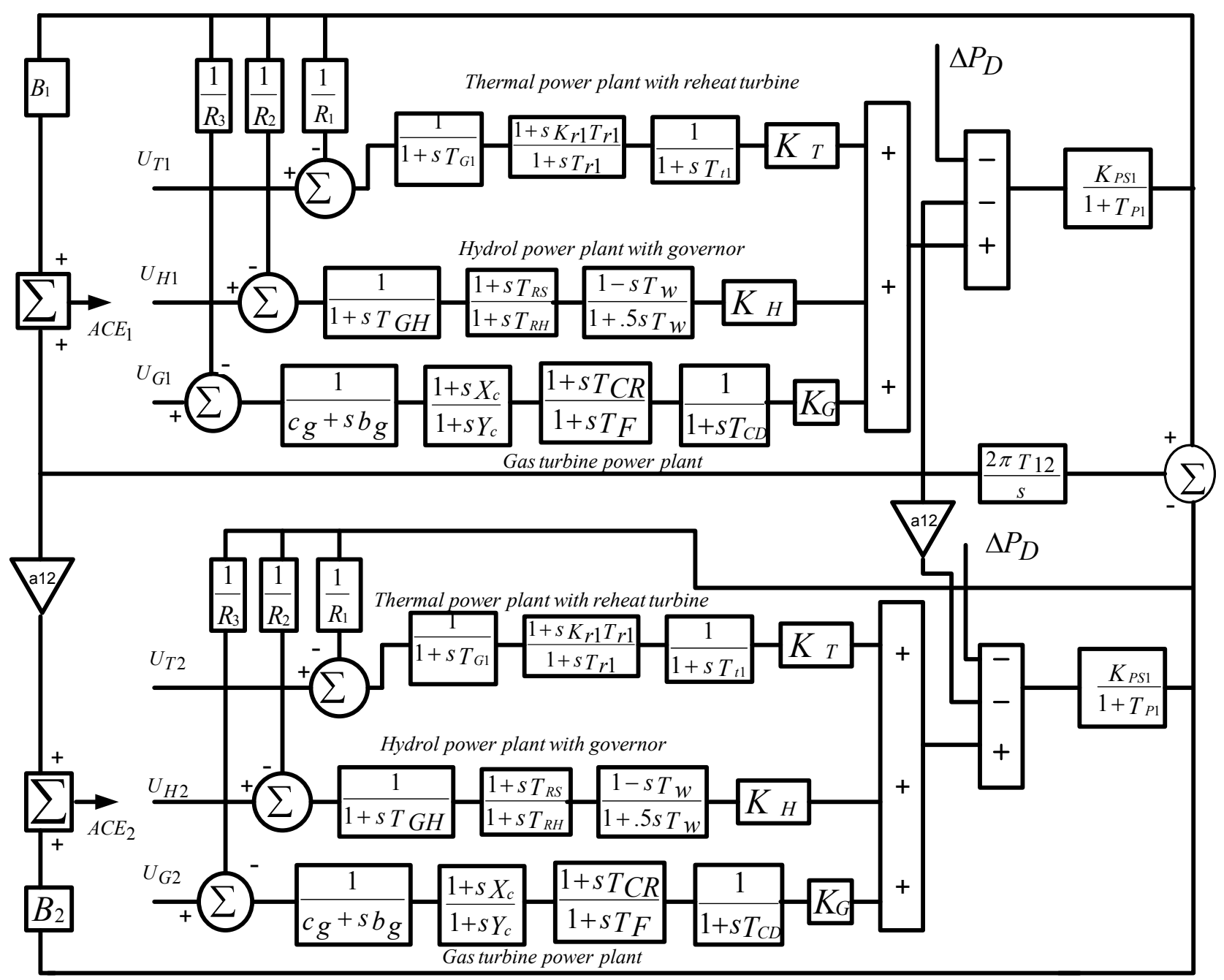

Fig. 1. Transfer function model of test system

The control outputs are represented as $U_{\mathrm{T}}$ for thermal, $\mathrm{U}_{\mathrm{H}}$ for hydro and $U_{G}$ for gas units. The participation factors are represented as $\mathrm{K}_{\mathrm{T}}$ for thermal, $\mathrm{K}_{\mathrm{H}}$ for hydro and $\mathrm{K}_{\mathrm{G}}$ gas units. $\mathrm{T}_{\mathrm{SG}}, \mathrm{T}_{\mathrm{T}}$ represents time constant of speed governor for thermal units and reheat steam turbine in second respectively. $\mathrm{T}_{\mathrm{W}}$ represents penstock base starting time of water in sec. $T_{R S}$ represents reset time for speed governor, $\mathrm{T}_{\mathrm{RH}}$ represents time constant for governor droop, $\mathrm{T}_{\mathrm{GH}}$ represents time constant for main servo of speed governor of hydro turbine in sec respectively. $X_{C}$ represents lead-time constants and $Y_{C}$ represents lag-time constants of speed governor for gas turbine in sec respectively. $c_{g}$ represents gas turbine and $b_{g}$ represents valve positioned based gas turbine constant. $\mathrm{T}_{\mathrm{F}}$ represents time constant of fuel and $T_{C R}$ represents time delay of combustion reaction in sec of gas turbine. $\mathrm{T}_{\mathrm{CD}}$ represents time constant of discharge volume for compressor based gas turbine in sec. $\mathrm{K}_{\mathrm{PS}}$ represents gain of power system in Hz/p.u.MW. TPS represents time constant of power system in sec. $\Delta \mathrm{F}, \Delta \mathrm{P}_{\mathrm{D}}$ are the variation in frequency and load respectively.

\subsection{Controller design with objective function}

Circuit diagram of PID controller is shown in Fig. 2.
Where $\mathrm{K}_{\mathrm{P}}$ : Proportional gain, $\mathrm{K}_{\mathrm{I}}$ : Integral gain and $\mathrm{K}_{\mathrm{D}}$ : Derivative gains. The general s-domain PID controller transfer function is given by.

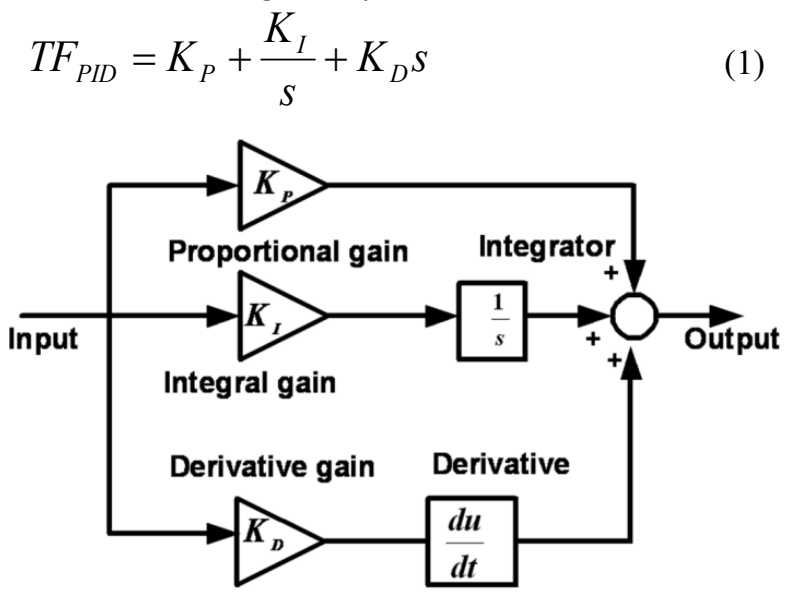

Fig. 2. PID controller structure

Errors inputs to the controllers of the corresponding ACE are mentioned in equations (2-3):

$$
\begin{aligned}
& A C E_{1}=e_{1}(t)=B_{1} \Delta F_{1}+\Delta P_{T i e} \\
& A C E_{2}=e_{2}(t)=B_{2} \Delta F_{2}-\Delta P_{T i e}
\end{aligned}
$$

\footnotetext{
*Corresponding author: rksahu_ee@vssut.ac.in
} 
The performance criteria suitable for AGC studies are Integral Time multiplied Absolute Error (ITAE) as reported in literature [15]. ITAE is used as objective function which is provided in equation (4):

$$
J=I T A E=\int_{0}^{t_{s i n}}\left(\left|\Delta F_{1}\right|+\left|\Delta F_{2}\right|+\left|\Delta P_{\text {Tie }}\right|\right) \cdot t \cdot d t
$$

Equation (5-6) represents the optimization problem for the design issue

Minimize the value of $\boldsymbol{J}$

Subject to

$$
\begin{aligned}
& K_{P \min } \leq K_{P} \leq K_{P \max } \\
& K_{I \text { min }} \leq K_{I} \leq K_{I \max } \\
& K_{D \text { min }} \leq K_{D} \leq K_{D \text { max }}
\end{aligned}
$$

The minimum parameters values are chosen as -2.0 and maximum value is 2.0 of PID controller.

\section{Search Group Algorithm}

A population-based optimization method as Search Group Algorithm was being proposed by M.S. Goncalves et al. [13].The important function of SGA is categorized into five steps is depicted in below.

\subsection{Phase-1: Initial Population}

Randomly initial population $\mathrm{P}$ is chosen based on equation (7)

$$
\begin{aligned}
P_{i j}=X_{j}^{\mathrm{min}} & +\left(X_{j}^{\mathrm{max}}-X_{j}^{\mathrm{min}}\right) U[0,1] \\
& \text { Where } j=1 \text { to } \mathrm{n}, i=1 \text { to } n_{p o p}
\end{aligned}
$$

$P_{i j}$ represents as the $j^{\text {th }}$ design variable of population $\mathrm{P}$ for $i^{\text {th }}$ individual. All design variables summation is n. $n_{p o p}$ signifies the total of population. The range of identical variable $U[0,1]$ is between 0 to 1 which is arbitrary in nature. The lower limit is $X_{j}^{\min }$ and the higher limit is $X_{j}^{\max }$ of $j^{\text {th }}$ design variable.

\subsection{Phase-2: Initial search group selection}

Initially the population has being formed after that objective function is evaluated, a benchmark tournament selection [13] is applied by selecting $n_{g}$ individuals from the population $\mathrm{P}$ to build the search group $\mathrm{R}$. In every cycle If $R_{i}$ denotes the $i^{\text {th }}$ row of $\mathrm{R}$, then $\mathrm{R}_{l}$ : denotes the finest design, $\mathrm{R}_{n g}$ : denotes the coarse design in $\mathrm{R}, \mathrm{n}_{g}$ : denotes the members count in search group.

\subsection{Phase-3: Selection of mutated search group}

New offspring's (individuals) are generated by substituting $\mathrm{n}_{\text {mut }}$ individuals from $\mathrm{R}$ to increase the capabilities of global population search which is evolved from equation (8)

$X_{j}^{m u t}=\mathrm{E}\left[R_{j}\right]+t \varepsilon \sigma\left[R_{j}\right]$, for $j=1, \ldots, \mathrm{n}$

Where $X_{j}^{m u t} \rightarrow \mathrm{j}^{\text {th }}$ design variable of known mutated individual.
$\mathrm{E} \rightarrow$ Mean, $\sigma \rightarrow$ Standard deviation, $\quad \varepsilon \rightarrow$ random variable

Choosing of worst objective function is being replaced by "inverse tournament" selection.

\subsection{Phase-4: Family generation of every search group member}

Family defines as the generation of set of offspring's (individuals) from search group member using perturbation analysed by equation (9).

$\mathrm{X}_{j}^{m u t}=R_{i j}+\alpha \varepsilon \quad$ for $j=1, \ldots . \mathrm{n}$

Where $\alpha \underset{\text { Controls }}{\longrightarrow}$ size of the perturbation

During the search process value of $\alpha$ reduces after subsequent iteration $\mathrm{k}$. which is mentioned in equation (10):

$\alpha^{k+1}=b \alpha^{k}$

Where in every iteration $\alpha^{k}$ reduces in such a manner which is described by parameter $b$ and controls the distance. Initially, value of $\alpha^{k}$ is chosen a maximum value to explore the design phase as a whole.

$\alpha^{k}$ ranges between $\alpha^{0} \leq \alpha^{k} \leq \alpha_{\text {min }}$

Where $\alpha_{\min } \rightarrow$ Minimum value of $\alpha^{k}$ to ascertain and nullify movement of new off springs (Individuals) also in last iteration of SGA.

$\alpha^{0} \rightarrow$ Initial iteration value of $\alpha$. Assume $F_{i} \rightarrow$ Family where $\mathrm{i}=1$ to $n_{g}$. The objective function decides the creation of number of offspring by every search group members. Total count of offspring (Individuals) maximizes based on the superiority of objective function. Keeping constant by calculating total number of design in each iteration which is represents as $\left(n_{p o p}-n_{g}\right)$.

\subsection{Phase-5: Selection of new search group}

Global phase algorithm defines as the novel search group emerges by key (best) global member of individual family in the initial $i t^{\max }$ iterations. Local phase of algorithm defines as the original search group is produced where it $\max _{\text {global }}$ is less than iteration number by the better $n_{g}$ individuals within the families. $i t^{\max } \rightarrow$ Maximum iterations, it global $_{\max } \rightarrow$ Maximum iterations in global phase.

\section{Firefly Algorithm}

Yang et al. [16] developed a meta-heuristic technique termed as Firefly Algorithm (FA) which is based on bioluminescence that is a biochemical process by the flashing characteristics (flashing light) of fireflies. For mating the flashing light may use as the main courtship signals $[17,18]$.It is based on the following three fire-flies characteristics:

Every firefly having unisex property gets attracted among them in spite of their sex.

Based on brightness the firefly gets attracted using distance parameters. 
The optimized objective function decides the brightness of a firefly. The Firefly algorithm is elaborated detail in [12].

\section{Analysis of results with discussion}

In this paper MATLAB with SIMULINK is used to design and simulate the model for studying the system. SGA programs are written separately with MATLAB(.m) program file using control parameters and SGA parameter by taking step load perturbation of $2 \%$ at $t=0.0 \mathrm{sec}$ in area-1. SGA parameter plays a prominent role and it is chosen according to literature [13]. Table 1 includes the control parameter values of SGA which is applied in the algorithm.

Table 1. SGA Parameter.

\begin{tabular}{|c|c|}
\hline Parameter & Value \\
\hline$\alpha^{\mathrm{o}}$ & 2 \\
\hline$n_{p o p}$ & 100 \\
\hline$\alpha_{\min }$ & 0.01 \\
\hline$i t^{\max }$ & 50 \\
\hline$i t_{\text {global }}^{\max }$ & $0.5 \times i t^{\max }$ \\
\hline$n_{g}$ & $0.2 \times n_{p o p}$ \\
\hline$n_{m u t}$ & $0.03 \times n_{p o p}$ \\
\hline $\mathrm{t}$ & $\begin{array}{l}\mathrm{t}=1, \mathrm{t}=2, \mathrm{t}=3 \text { are used for every } \\
\text { mutated individual }\end{array}$ \\
\hline
\end{tabular}

SGA/FA is taken to tune parameters of the PID controller separately. The unknown parameters of PID controller are recorded at the end of $\mathrm{it}^{\text {tmax }}$. A series of optimization process was conducted and the best final solution is chosen as final control parameters with minimum ITAE values. The optimized SGA based PID control parameter as well FA tuned PID control parameter are mentioned in Table 2.

Table 2. SGA and FA tuned controller Parameters.

\begin{tabular}{|c|c|}
\hline FA:PID & SGA:PID \\
\hline Unit1: Thermal & Unit1: Thermal \\
\hline $\mathrm{KP} 1=-1.9978$ & $\mathrm{KP} 1=1.9978$ \\
\hline $\mathrm{KI} 1=1.9978$ & $\mathrm{KI} 1=0.5126$ \\
\hline $\mathrm{KD} 1=1.0443$ & $\mathrm{KD} 1=1.991$ \\
\hline Unit 2: Hydro & Unit 2: Hydro \\
\hline $\mathrm{KP} 2=1.0443$ & $\mathrm{KP} 2=1.9978$ \\
\hline $\mathrm{KI} 2=-1.9959$ & $\mathrm{KI} 2=-0.1948$ \\
\hline $\mathrm{KD} 2=1.6992$ & $\mathrm{KD} 2=0.8454$ \\
\hline Unit 3: Gas & Unit 3: Gas \\
\hline $\mathrm{KP} 3=0.9696$ & $\mathrm{KP} 3=1.6877$ \\
\hline $\mathrm{KI} 3=1.2519$ & $\mathrm{KI} 3=1.9978$ \\
\hline $\mathrm{KD} 3=-0.4538$ & $\mathrm{KD} 3=-0.4538$ \\
\hline
\end{tabular}

At $\mathrm{t}=0.0 \mathrm{sec}$ a $2 \%$ Step Load Perturbation (SLP) is applied in area-1, the SGA tuned PID controller and FA tuned PID controller system performance is demonstrated in Table 3. The superiority of SGA tuned PID controller with less ITAE value (ITAE=0.2947) than FA tuned PID controller (ITAE $=1.6463)$ is depicted in Table 3 using the same controller with objective function. Again the settling times in frequency variation and deviations in tie power with SGA optimized PID controller are improved compare to FA tuned PID controller. Hence it is clear that SGA superior than FA. The system dynamic response deviations in frequency \& deviations in tie-line power is depicted in Figs. 3-5.

Table 3. Comparative performance index values.

\begin{tabular}{|c|c|c|c|c|}
\hline Techniques/ & \multicolumn{2}{|c|}{ Settling times Ts } & \multirow{2}{*}{ ITAE } \\
\cline { 2 - 4 } parameters & $\Delta \mathrm{F}_{1}$ & $\Delta \mathrm{F}_{2}$ & $\Delta \mathrm{P}_{\text {tie }}$ & \\
\hline FA:PID & 2.34 & 2.33 & 1.91 & 1.6463 \\
\hline SGA:PID & 1.13 & 0.94 & 1.07 & 0.2947 \\
\hline
\end{tabular}

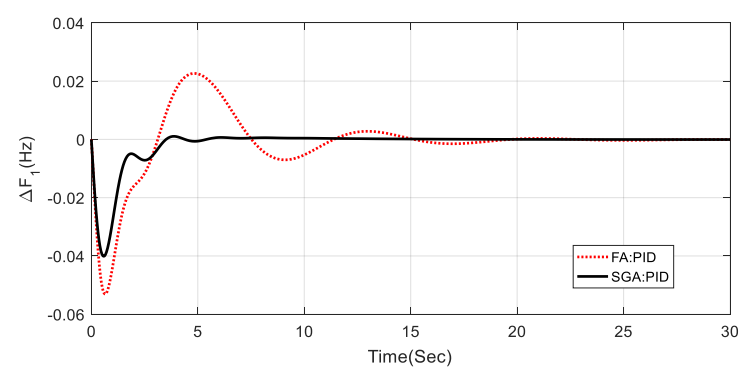

Fig. 3. $\Delta \mathrm{F}_{1}$ with $2 \%$ SLP in area-1.

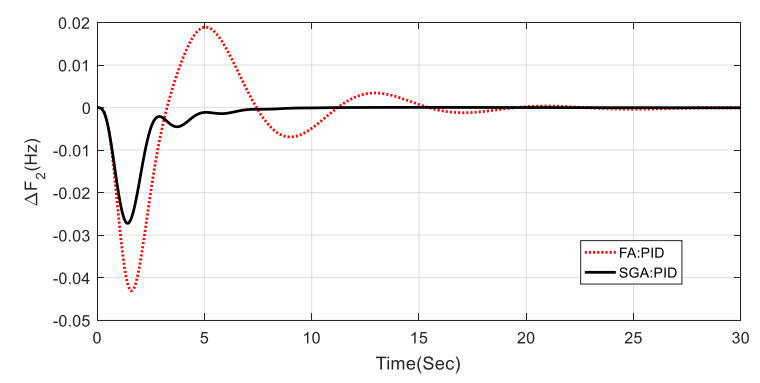

Fig. 3. $\Delta \mathrm{F}_{2}$ with $2 \%$ SLP in area-1.

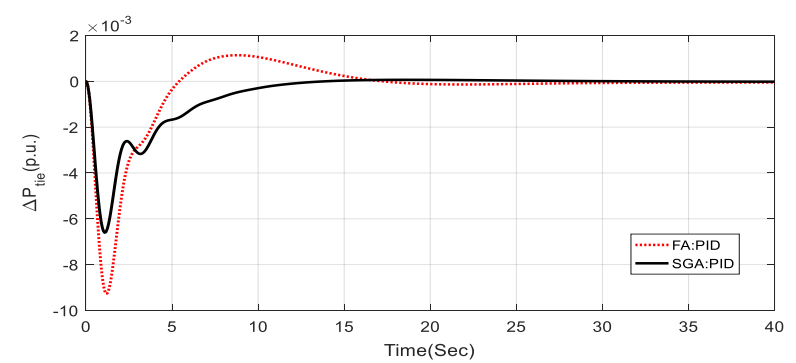

Fig .5. $\Delta \mathrm{P}_{\text {tie }}$ with $2 \%$ SLP in area-1.

This clearly signifies from the Figs. 3-5 that best dynamic performance as well as better response is achieved by SGA compared to FA technique.

Further at $\mathrm{t}=0.0 \mathrm{sec}$ a simultaneous SLP of $2 \%, 1 \%$ in area-1 \& area- 2 respectively are applied. The dynamic performance with SGA tuned PID controller \& FA tuned PID controller are demonstrated in Figs. 6-8. It is obvious from Figs. 6-8 that, proposed SGA optimized PID controllers based on the location of the disturbance changes also performs satisfactorily and gives robust result. 


\section{Sensitivity analysis}

Sensitivity analysis is perform to test the robustness of the proposed approach with variation in the system parameters and operating conditions.

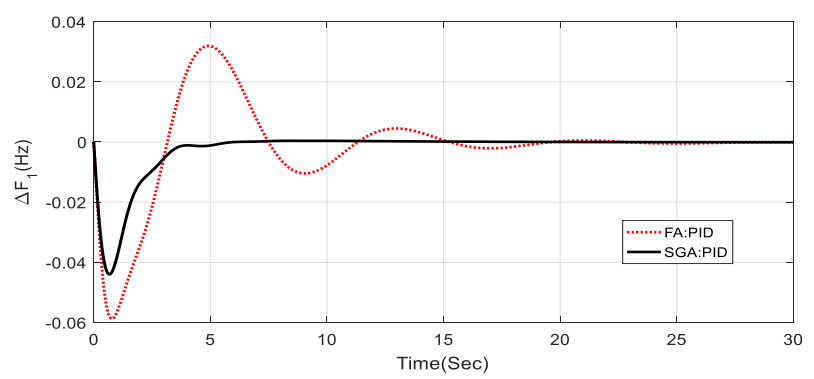

Fig. 6. $\Delta \mathrm{F}_{1}$ for $2 \% \& 1 \%$ SLP in area- 1 and in area- 2 .

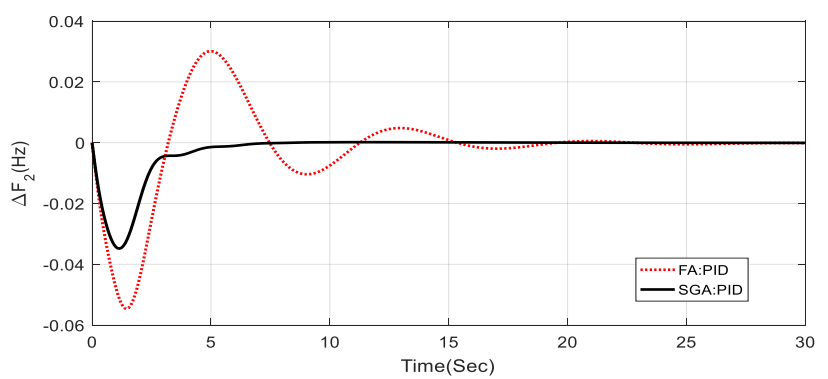

Fig. 7. $\Delta \mathrm{F}_{2}$ for $2 \% \& 1 \%$ SLP in area- 1 and in area-2.

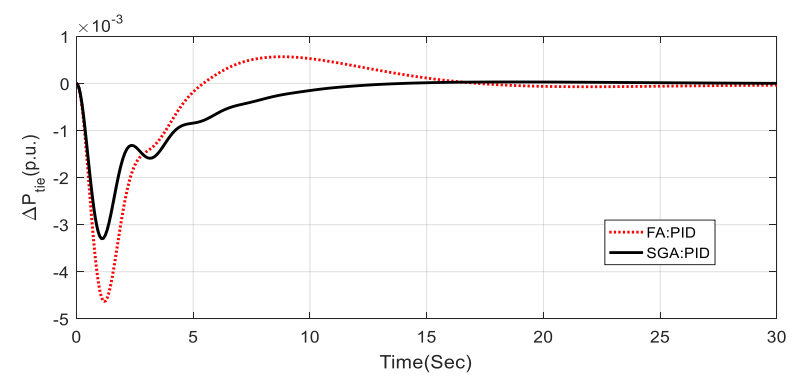

Fig.8. $\Delta \mathrm{P}_{\text {tie }}$ for $2 \% \& 1 \%$ SLP in area-1 and in area- 2 .

The nominal values varying from $+25 \%$ to $-25 \%$ in the operating load condition and system parameters (given in appendix) mentioned in Table 4. It is clearly depicts the system time constants and variations on operating loading conditions over the system performance are negligible as well as reflect the similarity in performance indexes values.

Fig. 9 shows $\pm 25 \%$ variations in the loading conditions with nominal parameters for the deviation in frequency response of area-1. From Fig. 9 it clearly reveals that the deviation in loading condition over the system performance is evaluated as negligible. To evaluate the supremacy of the proposed approach a random step load change is applied in area-1. Fig.10 depicts the random step load based pattern (magnitude and duration) applied to the test system [9]. Fig.11 shows the transient responses for $\Delta \mathrm{F}_{1}$. From which it can be conclude that the proposed SGA tuned PID controller which provides superior damping compare to other.

\section{Conclusions}

In the present work, SGA/FA methods are used to tune PID controller parameters in a two-area six-unit power system. The superiority of the SGA technique is demonstrated by comparing the results with a FA optimization technique. The result reveals that SGA tuned

Table 4. Sensitivity analysis.

\begin{tabular}{|c|c|c|c|c|c|}
\hline \multirow{3}{*}{$\begin{array}{l}\text { Parameter } \\
\text { variation }\end{array}$} & \multirow[t]{3}{*}{$\%$} & \multicolumn{4}{|c|}{ Performance index } \\
\hline & & \multicolumn{3}{|c|}{$\begin{array}{l}\text { Settling time }(2 \% \text { band }) \quad T_{s} \\
\text { (Sec) }\end{array}$} & \multirow[t]{2}{*}{ ITAE } \\
\hline & & $\Delta \mathrm{F}_{1}$ & $\Delta \mathrm{F}_{2}$ & $\Delta \mathrm{P}_{\text {tie }}$ & \\
\hline Nominal & 0 & 1.13 & 0.94 & 1.07 & 0.2947 \\
\hline \multirow{2}{*}{$\begin{array}{r}\text { Loading } \\
\text { condition }\end{array}$} & +25 & 1.12 & 0.96 & 1.06 & 0.2949 \\
\hline & -25 & 1.14 & 0.93 & 1.07 & 0.2947 \\
\hline \multirow[t]{2}{*}{$\mathrm{T}_{\mathrm{G}}$} & +25 & 1.15 & 1.01 & 1.09 & 0.2948 \\
\hline & -25 & 1.21 & 1.02 & 1.16 & 0.2954 \\
\hline \multirow[t]{2}{*}{$\mathrm{T}_{\mathrm{GH}}$} & +25 & 1.12 & 0.93 & 1.07 & 0.2956 \\
\hline & -25 & 1.11 & 0.95 & 1.04 & 0.2935 \\
\hline \multirow[t]{2}{*}{$\mathrm{T}_{\mathrm{T}}$} & +25 & 1.37 & 1.19 & 1.31 & 0.3061 \\
\hline & -25 & 1.07 & 0.91 & 1.02 & 0.2949 \\
\hline \multirow{2}{*}{$\mathrm{T}_{\mathrm{RH}}$} & +25 & 1.12 & 0.86 & 0.99 & 0.3028 \\
\hline & -25 & 1.24 & 1.13 & 1.22 & 0.2965 \\
\hline \multirow{2}{*}{$\mathrm{T}_{\mathrm{CD}}$} & +25 & 1.13 & 0.93 & 1.06 & 0.2943 \\
\hline & -25 & 1.14 & 0.99 & 1.08 & 0.2950 \\
\hline \multirow{2}{*}{ B } & +25 & 1.05 & 0.85 & 1.00 & 0.2601 \\
\hline & -25 & 1.33 & 1.16 & 1.15 & 0.3701 \\
\hline \multirow{2}{*}{$\mathrm{R}$} & +25 & 1.18 & 0.90 & 1.06 & 0.3020 \\
\hline & -25 & 0.77 & 1.03 & 1.08 & 0.2923 \\
\hline
\end{tabular}

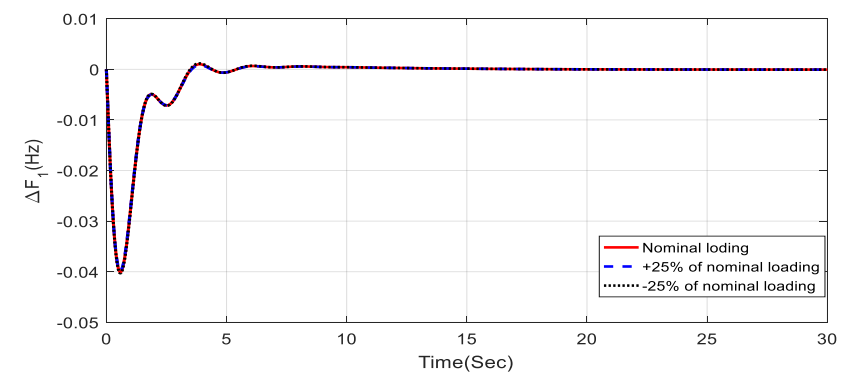

Fig. 9. $\Delta \mathrm{F}_{1}$ with change of loading.

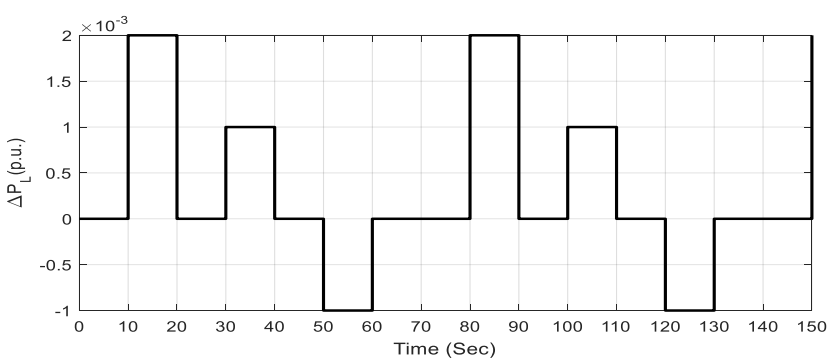

Fig. 10. Stochastic step load based pattern

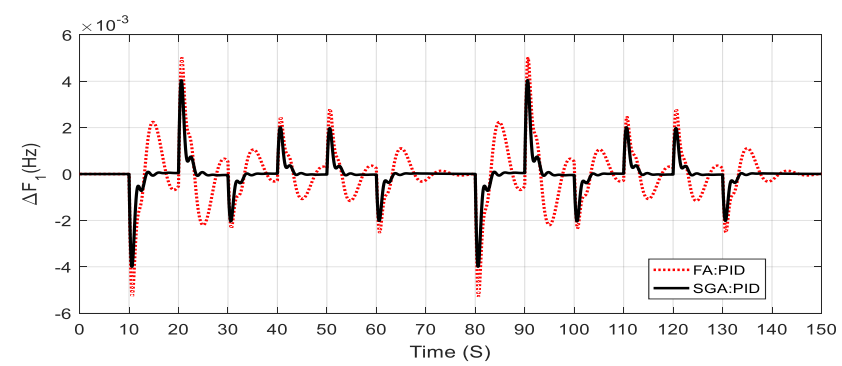

Fig. 11. Variation in $F_{1}$ 
PID controller offers significant improvement in the response than the FA tuned PID controller. After that sensitivity analysis is carried out to demonstrate the robustness of the proposed approach to wide variations of system parameter, operating loading conditions with respect to nominal values as well as random load disturbance. It is evident from simulation results that the proposed SGA optimized PID controller is much more effective, robust and furnish best system performance as comparison to FA tuned PID controller.

\section{Appendix}

The investigated system nominal parameters are: [14] $\mathrm{R}_{1}=\mathrm{R}_{2}=\mathrm{R}_{3}=2.4 \mathrm{~Hz} /$ p.u; $\mathrm{B}_{1}=\mathrm{B}_{2} 0.4312$ p.u., $\mathrm{T}_{12}=0.0433$, $\alpha_{12}=-1 ; \mathrm{T}_{\mathrm{SG}}=0.08 \mathrm{sec} ; \mathrm{T}_{\mathrm{T}}=0.3 \mathrm{~s} ; \mathrm{T}_{\mathrm{r}}=10 \mathrm{~s} ; \mathrm{K}_{\mathrm{r}}=0.3 ; \mathrm{K}_{\mathrm{T}}=$ $0.543478 ; \mathrm{T}_{\mathrm{PS}}=11.49 \mathrm{~s} ; \mathrm{K}_{\mathrm{PS}}=68.9566 \mathrm{~Hz} /$ p.u. $\mathrm{MW} ; \mathrm{K}_{\mathrm{H}}=$ $0.326084 ; \mathrm{T}_{\mathrm{W}}=1.0 \mathrm{~s} ; \mathrm{T}_{\mathrm{RS}}=5 \mathrm{~s} ; \mathrm{T}_{\mathrm{GH}}=0.2 \mathrm{~s}, \mathrm{~T}_{\mathrm{RH}}=28.75 \mathrm{~s}$; $\mathrm{X}_{\mathrm{C}}=0.6 \mathrm{~s}, \mathrm{Y}_{\mathrm{C}}=1 \mathrm{~s}, \mathrm{~T}_{\mathrm{F}}=0.23 \mathrm{~s} ; \mathrm{T}_{\mathrm{CD}}=0.2 \mathrm{~s} ; \mathrm{T}_{\mathrm{CR}}=0.01 \mathrm{~s}, \mathrm{~K}_{\mathrm{G}}=$ $0.130438 ; \mathrm{cg}=1, \mathrm{bg}=0.05 \mathrm{~s}$.

\section{References}

1. H. Bevrani, Robust Power System Frequency Control, Springer, (2009)

2. H. Bervani, T. Hiyama, Intelligent Automatic Generation control, CRC Press, (2011)

3. O.I. Elgerd, Electric Energy Systems Theory - An Introduction, Tata McGraw Hill, New Delhi, (2000)

4. K.P. Ibraheem, D.P. Kothari, Recent philosophies of automatic generation control strategies in power systems, IEEE Trans. Power Syst., 20, 346-357, (2005).

5. J. Nanda, A. Mangla, S. Suri, Some findings on automatic generation control of an interconnected hydrothermal system with conventional controllers, IEEE Trans. on Energy Conv.,21, 187-193, (2006)

6. L.C. Saikia, J. Nanda, S. Mishra, Performance comparison of several classical controllers in AGC for multi-area interconnected thermal system, Int. J. Elect. Power \& Energy Systs., 33(3), 394-401, (2011)

7. R. K. Sahu, T.S. Gorripotu, S.Panda, Automatic generation control of multi-area power systems with diverse energy sources using teaching learning based optimization algorithm, Engg. Science \& Technology, An International Journal, 19, 113-134, (2016)

8. E. S. Ali, S. M. Abd-Elazim, Bacteria foraging optimization algorithm based load frequency controller for interconnected power system, Int.
J. Elect. Power \& Energy Systs., 33(3), 633-638, (2011).

9. R.K. Sahu, S. Panda, U.K.Rout, D.K. Sahoo, Teaching learning based optimization algorithm for automatic generation control of power system using 2-DOF PID controller, Int. J. Elect. Power \& Energy Systs., 77(3), 287-301, (2016).

10.G. Sharma, I. Nasiruddin, K.R. Niazi, R.C. Bansal, Optimal AGC of a multi-area power system with parallel $A C / D C$ tie lines using output vector feedback control strategy, Int. J. Elect. Power \& Energy Systs., 81, 22-31, (2016)

11.D. Guha, P.K. Roy, S. Banerjee, Load frequency control of interconnected power system using grey wolf optimization, Swarm and Evol. Compt., 27, 97-115, (2016)

12.S. Padhan, R.K. Sahu, S. Panda, Application of firefly algorithm for load frequency control of multi-area interconnected power system', Elect. Power Compts and Syst., 42(13), 1419-1430, 2014.

13.M.S. Gonçalves, R. H. Lopez, L.F. Fadel, Search group algorithm: A new metaheuristic method for the optimization of truss structures design, Computers and Structures, 153, 165-184, (2015).

14.K.P.S. Parmar, S. Majhi, D.P. Kothari, Load frequency control of a realistic power system with multi-source power generation, Int. J. Elect. Power \& Energy Systs., 42, 426-433, (2012).

15.H. Shabani, B.Vahidi, M.A. Ebrahimpour, Robust PID controller based on imperialist competitive algorithm for load-frequency control of power systems, ISA Trans., 52, 88-95, (2012)

16.X.S. Yang, Nature-Inspired Metaheuristic Igorithms, Luniver Press, UK, (2008)

17.X.S. Yang, Firefly algorithms for multimodal optimization, in: Stochastic Algorithms: Foundations and Applications, SAGA Lecture Notes in Computer Sciences, 5792, 169-178, (2009)

18.X.S. Yang, Firefly algorithm, stochastic test functions and design optimization, International Journal of Bio-inspired Computation, 2, 78-84, (2010). 